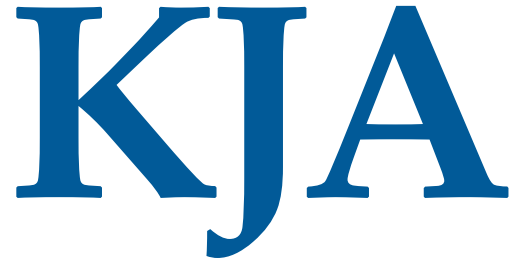

Korean Journal of Anesthesiology

\section{Corrigendum}

Korean J Anesthesiol 2021;74(2):188

https://doi.org/10.4097/kja.19305.e1

pISSN 2005-6419• elSSN 2005-7563

\title{
Fluid responsiveness in the pediatric population
}

\section{Ji-Hyun Lee, Eun-Hee Kim, Young-Eun Jang, Hee-Soo Kim, Jin-Tae Kim}

Department of Anesthesiology and Pain Medicine, Seoul National University Hospital, Seoul National University College of Medicine, Seoul, Korea

Korean J Anesthesiol 2019 October 72(5): 429-440

https://doi.org/10.4097/kja.19305

The article by Lee et al. entitled, "Fluid responsiveness in the pediatric population" (Korean J Anesthesiol 2019 Oct; 72(5): 429-440) should add the following explanation in Fig. 2.

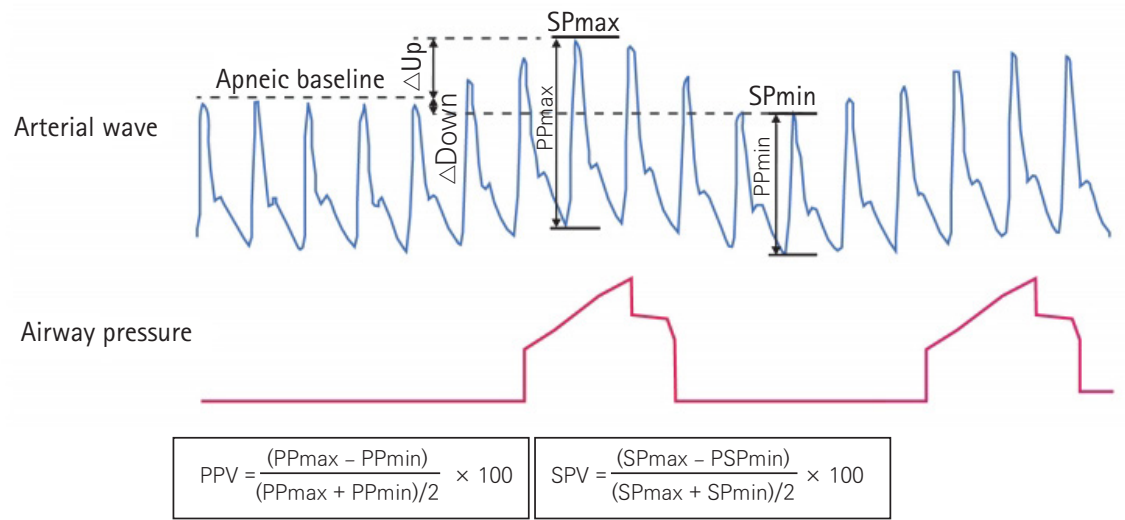

The unit of the suggested equations for PPV and SPV is \%.

Although SPV (mmHg) is traditionally calculated as SPmax-SPmin or $\Delta \mathrm{Up}+\Delta \mathrm{Down}$, SPV $(\%)$ has been used for pediatric patients.

(C) The Korean Society of Anesthesiologists, 2021

(c) This is an open-access article distributed under the terms of the Creative Commons Attribution Non-Commercial License (http://creativecommons.org/licenses/ by-nc/4.0/), which permits unrestricted non-commercial use, distribution, and reproduction in any medium, provided the original work is properly cited. 